\title{
Tumor de Células de la Granulosa del Testículo, Tipo Juvenil: Reporte de un Caso y Revisión de la Literatura
}

\author{
Granulosa Cell Tumor of Testis, Juvenile Type: Case Report and Review of Literature
}

\author{
***Oscar Tapia E.; "Carlos Delgado S. M.; **Enrique Bellolio J. \& ** Miguel Villaseca H.
}

TAPIA, E. O.; DELGADO, S. M. C.; BELLOLIO, J. E. \& VILLASECA, H. M. Tumor de células de la granulosa del testículo, tipo juvenil: reporte de un caso y revisión de la literatura. Int. J. Morphol., 28(2):477-482, 2010.

RESUMEN: El Tumor de Células de la Granulosa Juvenil (TCGJ) del testículo es una entidad clínico-patológica poco frecuente, que típicamente se presenta en la edad pediátrica representando el $15 \%$ de los tumores del estroma gonadal. Su comportamiento biológico es considerado benigno y la orquiectomía considerada curativa en estos pacientes. Se presenta el caso de un lactante de sexo masculino de 3 meses de edad con un TCGJ del testículo diagnosticado en la Unidad de Anatomía Patológica del Hospital Hernán Henríquez Aravena de Temuco.

PALABRAS CLAVE: Neoplasia testicular; Tumor de células de la granulosa.

\section{INTRODUCCIÓN}

El Tumor de Células de la Granulosa Juvenil (TCGJ) del testículo es una entidad clínico-patológica poco frecuente con una frecuencia estimada de 0,5/100,000niños. Típicamente se presenta en la edad pediátrica, siendo el más frecuente de los tumores del estroma gonadal en niños, representando el $15 \%$ de los tumores de este grupo y $6 \%$ de los tumores testiculares infantiles (Metcalfe et al., 2003; Peterson \& Skoog, 2008; Thomas et al., 2001). Su comportamiento biológico es considerado benigno, ya que recurrencia ni metástasis han sido reportadas, siendo por tanto la orquiectomía considerada como tratamiento curativo en estos pacientes (Dudani et al., 2008; Fagin et al., 2003). Su presentación clínica esta asociado en algunos casos a malformaciones del tracto uro-genital o anomalías genéticas que comprometen al cromosoma Y (Chan et al.; Young et al., 1985).

Se presenta el caso de un lactante de sexo masculino de 3 meses de edad con un TCGJ del testículo diagnosticado en la Unidad de Anatomía Patológica del Hospital Hernán Henríquez Aravena de Temuco, Chile.

\section{CASO CLÍNICO}

Antecedentes perinatales: Mujer de 36 años, sin antecedentes mórbidos de importancia. Fórmula obstétrica G3P2A0. Parto pre-término vaginal de 34 semanas. Recién nacido de sexo masculino de 34 semanas, adecuado para la edad gestacional, puntaje de apgar 9 y 10 al minuto 1 y 5 respectivamente.

En control de segundo mes de vida se pesquizó aumento de volumen testicular izquierdo. Al examen se constató masa testicular izquierda indurada de aproximadamente $3 \mathrm{~cm}$ de diámetro mayor, no doloroso y sin compromiso escrotal; testículo derecho y pene sin alteraciones. El estudio con ultrasonido demostró testículo aumentado de tamaño de 25 x 35 x $20 \mathrm{~mm}$. de parénquima heterogéneo con múltiples imágenes anecogénicas de hasta $14 \mathrm{~mm}$. rodeadas de tejido sólido y acentuada vascularización al doppler color. El estudio serológico para marcadores tumorales (a-feto proteína y hormona gonadotropina coriónica sub-unidad b) fueron normales. Se complementó estudio con tomografía computada (TC) de pelvis, abdomen y tórax las que no demuestran lesiones secundarias.

\footnotetext{
* Departamento de Anatomía Patológica. Facultad de Medicina. Universidad de La Frontera. Temuco, Chile.

** Scentifical and Technological Bioresources Nucleus (BIOREN).
} 
Se efectuó orquiectomía izquierda, constatándose al examen anatomo-patológico un testículo de $15 \mathrm{~g}$ de 45 x 25 x $20 \mathrm{~mm}$ y consistencia firme. La superficie de corte presenta un reemplazo del parénquima testicular por múltiples lesiones quísticas que oscilan entre 3 y $15 \mathrm{~mm}$ con contenido mucoideo y áreas sólidas blanquecino amarillentas (Fig. 1). Al examen histológico se observan espacios quísticos revestidos por un número variable de capas de células de la granulosa que semejan al folículo ovárico rellenos por un material basófilo. Las células presentan formas poliédricas, con citoplasma escaso débilmente eosinófilo y núcleos redondeados u ovoides, hipercromáticos, sin hendiduras nucleares y un recuento mitótico de 6 en 10 campos de aumento seco mayor. No se encontraron cuerpos de Call-Exner. Alrededor de estas células, se observan células fusiformes,

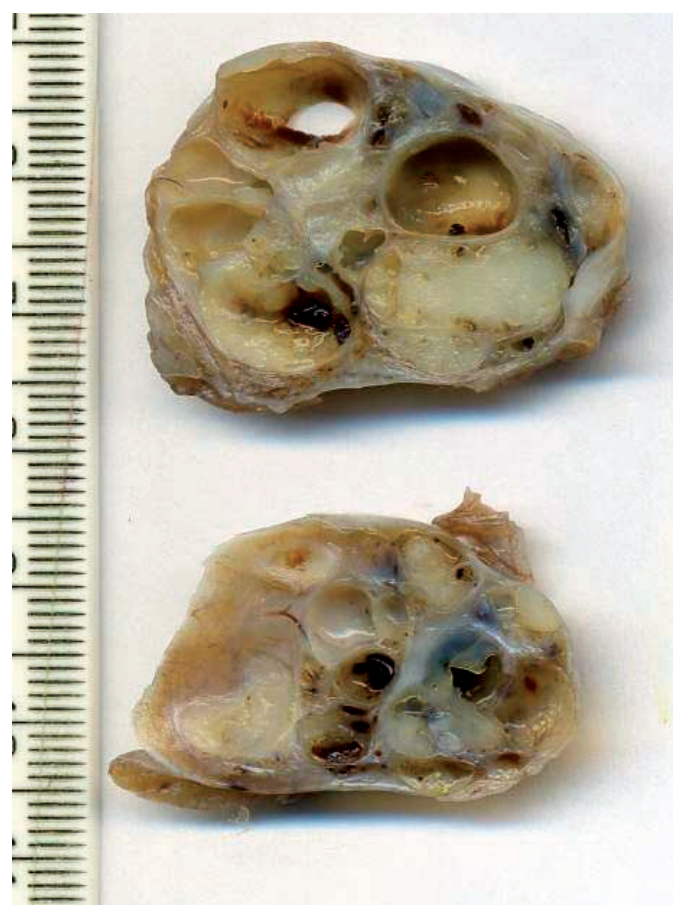

Fig. 1. Se aprecia tumor de $45 \times 25 \mathrm{~mm}$, blanquecino amarillento, bien delimitado con múltiples áreas quísticas que alternan con áreas sólidas. No se observa necrosis.

semejantes a las células de la teca con un estroma fibroconectivo muy vascularizado donde se reconocían tubulos seminiferos inmaduros remanentes. El cordón espermático no presenta alteraciones evidentes (Figs. 2 y 3 ).

No se registraron complicaciones post-operatorias. A los 8 meses post-cirugía, el paciente se encuentra sano, sin evidencia de enfermedad en TC de tórax-abdomen y pelvis.

\section{DISCUSIÓN}

El TCGJ del testículo es una entidad clínico-patológica poco frecuente descrita por primera vez por Crump (1983). En población pre-púber su frecuencia estimada es de $0,5 / 100,000$, sin embargo, constituye la neoplasia del testículo mas frecuente en los primeros 6 meses de vida representando el $15 \%$ de los tumores del estroma gonadal en niños y el 6\% de los tumores testiculares infantiles. Típicamente se presenta en la edad pediátrica, desde el periodo neonatal hasta los 21 meses, existiendo incluso reportes con diagnóstico ecográfico ante-natal (Metcalfe et al.; Peterson et al.; Thomas et al.).

Su comportamiento biológico es considerado benigno, ya que no se ha reportado recurrencia ni metástasis, siendo por tanto la orquiectomía el tratamiento recomendado como curativo para estos pacientes (Dudani et al.; Fagin et al.; Young et al., 1985; Lin et al., 2008).

Clínicamente, el TCGJ puede afectar al testículo en cualquiera de sus localizaciones: escrotal, inguinal o intraabdominal. Este se presenta como una masa testicular indurada, no dolorosa, sin predisposición por lateralidad, reportándose malformaciones genito-urinarias asociadas tales como genitales externos ambiguos e hipospadia en el $17 \%$ de los casos. Así también en el $20 \%$ se han descrito anomalías en el cromosoma Y. A diferencia de aquellos tumores localizados en el ovario, no han sido reportadas disfunciones endocrinas secundarias (Chan et al., 1997; Young et al.; Tanaka et al., 1994; Alexiev et al., 2007).

Macroscópicamente es un tumor parcialmente encapsulado cuyo tamaño varía de 0,8 a $6,5 \mathrm{~cm}$ y caracterizado por presentar múltiples áreas quísticas de paredes delgadas rellenas por material mucoideo que alterna con áreas sólidas pardo amarillentas, sin presentar necrosis o hemorragia (Metcalfe et al.; Thomas et al.; Fagin et al.; Young et al.).

Histológicamente, la lesión presenta un doble patrón: folicular y sólido. Los folículos son de tamaño variable confiriéndole la apariencia macroscópica quística y rellenos por un material esosinófilo o basófilo, positivo para tinciones de mucinas. De acuerdo al grado de dilatación quística, los folículos están revestidos por un número variable de capas de células de la granulosa las presentan núcleos redondeados u ovoideos con nucleólo pequeño y escaso citoplasma eosinófilo las que a su vez están rodeadas por células fusiformes que semejan a células de la teca. Los focos sólidos, típicamente muestran un patrón nodular inmersos en un estroma fibroconectivo bien vascularizado y conformados por grupos de células de la granulosa rodeadas por célu- 

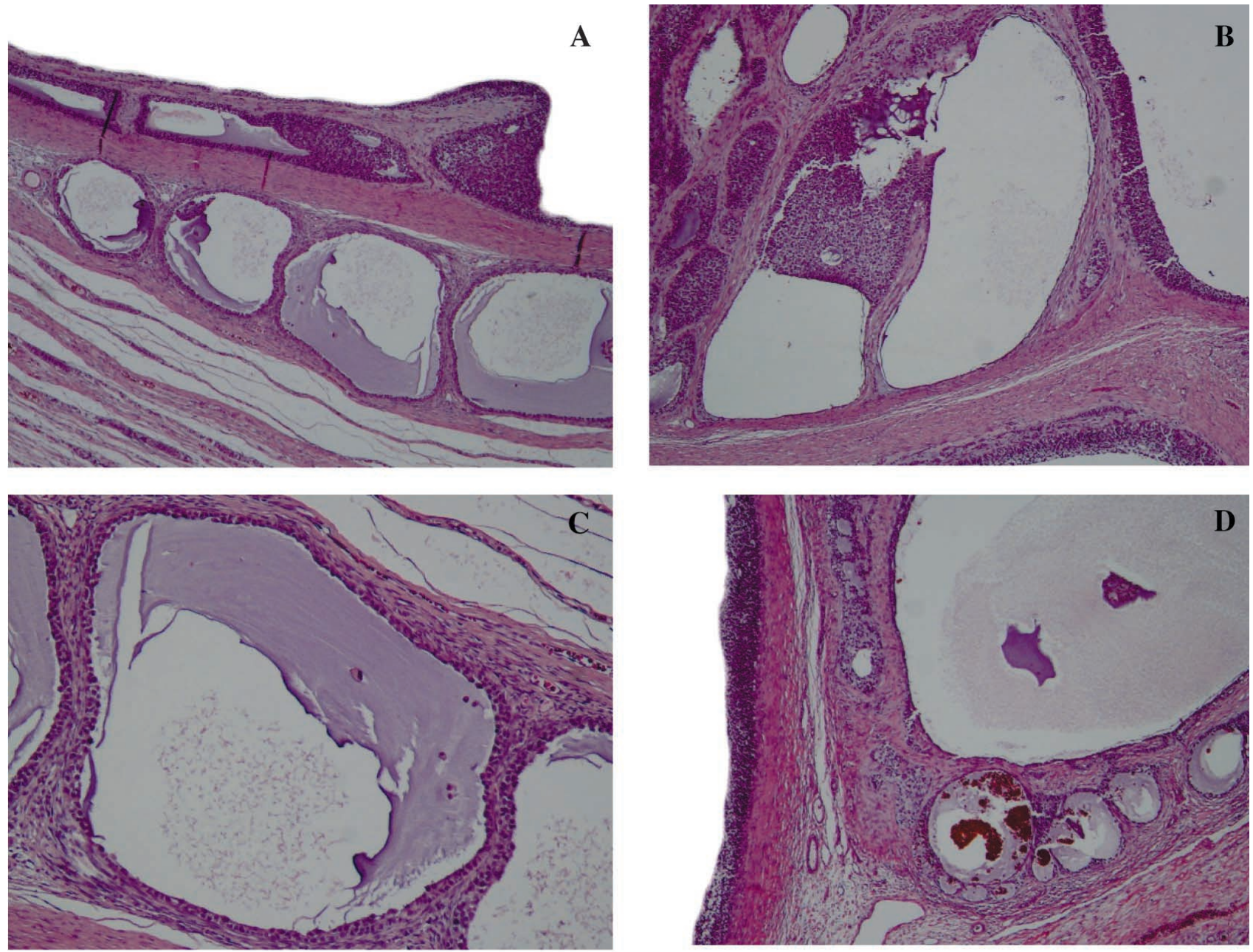

$\mathbf{E}$
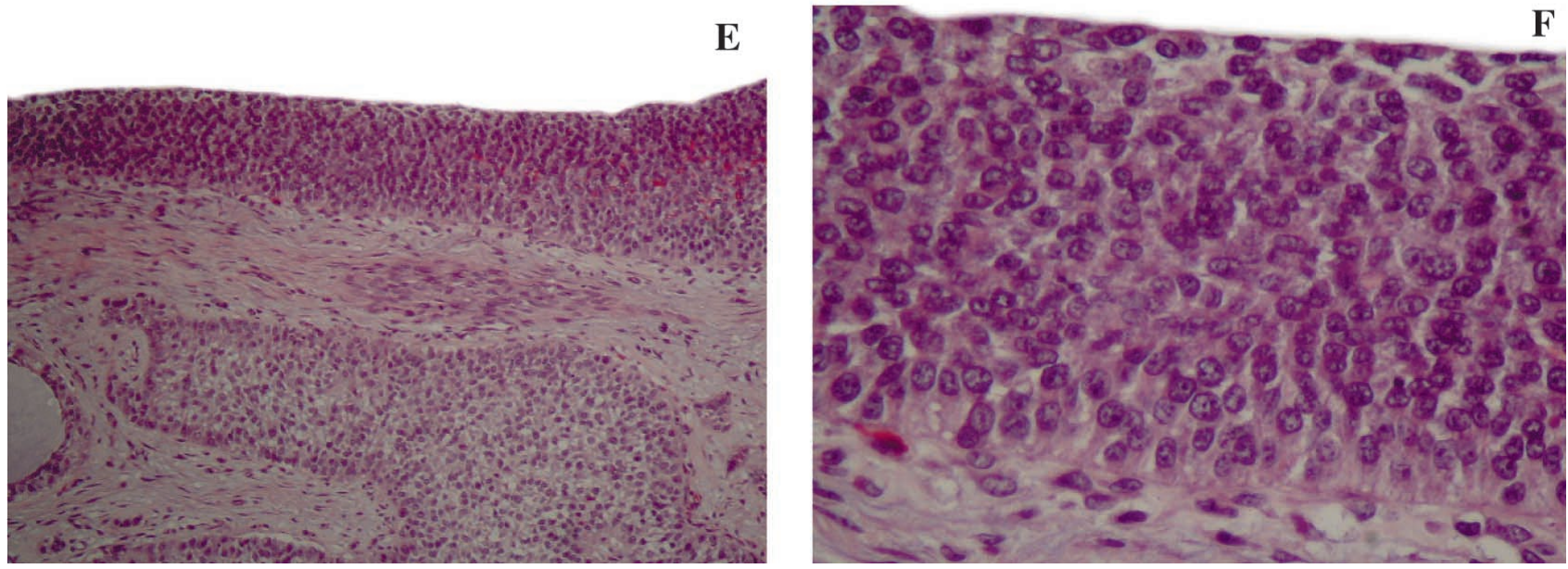

Fig. 2. (H-E, A: 40x, B-D: 100x, E-F: 400x). A-D: Se aprecia patrón folicular con espacios quísticos de tamaño variable, revestidos por células de la granulosa y rellenos por material basófilo. E-F: Se reconocen células con núcleos redondeados u ovoides sin hendiduras nucleares, nucléolos pequeños y citoplasma escaso débilmente eosinófilo. 

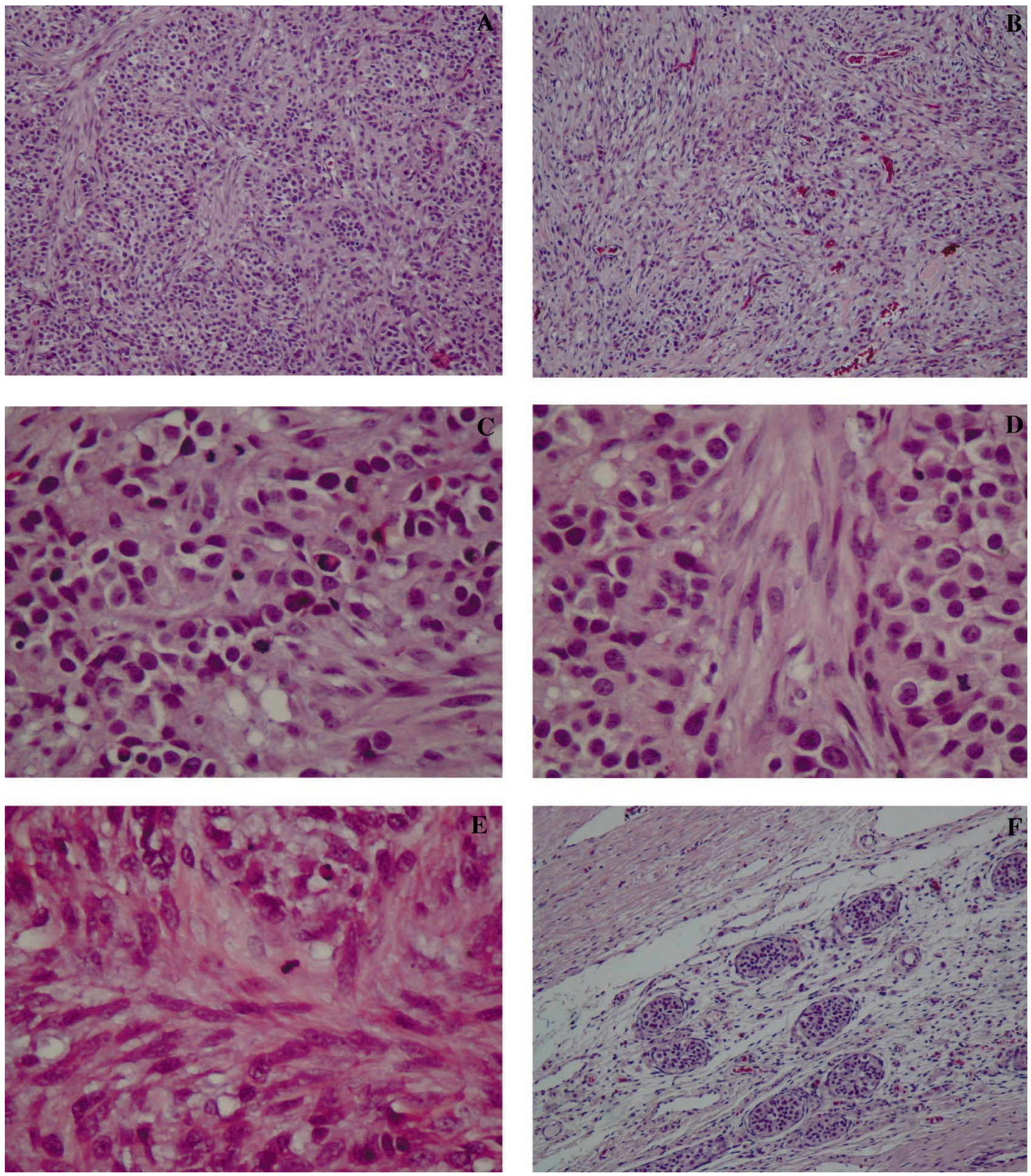

Fig. 3. (H-E, A-B: 40x; C-E: 400x; F: 100x). A-B: Se aprecia un estroma fibroconectivo muy vascularizado y un patrón de crecimiento tumoral sólido. C-E: Los nidos sólidos están conformados por grupos de células de la granulosa rodeadas por células fusiformes tipo musculo-liso, reconociéndose algunas mitosis. F: Túbulos seminíferos inmaduros remanentes presentes en la periferia del tumor. 
las fusiformes tipo musculo-liso. Las mitosis en general son escasas aunque en ocasiones pueden ser numerosas con recuentos de hasta 33 mitosis en 10 campos de aumento seco mayor (400x). En la periferia del tumor pueden observarse remanentes de túbulos seminíferos inmaduros. Cabe destacar que a diferencia del tumor de células de la granulosa del adulto, no se observan las típicas hendiduras nucleares ni tampoco cuerpos de Call-Exner (Metcalfe et al.; Thomas et al.; Fagin et al.; Young et al.; Alexiev et al.; Barroca et al., 2007; Lawrence et al., 1985).

Inmunofenotípicamente, las células tumorales demuestran positividad para vimentina e inhibina, demostrán- dose también que el tumor presenta una doble diferenciación con expresión de marcadores tanto epiteliales como de músculo (Alexiev et al.; Barroca et al.).

El diagnóstico diferencial de este tumor se establece con otras lesiones quísticas testiculares tales como el teratoma quístico testicular, tumor del saco vitelino, displasia testicular quística, linfangioma quístico o la transformación quística del testículo tras la torsión del cordón espermático, siendo de vital importancia el correcto diagnóstico de cada uno de ellos pues presentan pronósticos y conductas terapéuticas muy distintas (Young et al.; Barroca et al.; Levy et al., 1994).

TAPIA, E. O.; DELGADO, S. M. C.; BELLOLIO, J. E. \& VILLASECA, H. M. Granulosa cell tumor of testis, juvenile type: case report and review of literature. Int. J. Morphol., 28(2):477-482, 2010.

SUMMARY: Juvenile granulosa cell tumor of the testis (JGCT) is a uncommon clinical and pathological entity, typically present in children accounting for $15 \%$ of gonadal stromal tumors. Its biological behavior is deemed benign and orchiectomy considered curative in these patients. We present a case of a male infant 3 months of age with a JGCT diagnosed in the Pathology Unit of Hospital Hernán Henríquez Aravena, Temuco.

KEY WORDS: Testicular neoplasms; Granulosa cell tumor.

\section{REFERENCIAS BIBLIOGRÁFICAS}

Alexiev, B. A.; Alaish, S. M. \& Sun, C. C. Testicular juvenile granulosa cell tumor in a newborn: case report and review of the literature. Int. J. Surg. Pathol., 15(3):321-5, 2007.

Barroca, H.; Gil-da-Costa, M. J. \& Mariz, C. Testicular juvenile granulosa cell tumor: a case report. Acta Cytol., 51(4):634-6, 2007.

Chan, Y.; Restall, P. \& Kimble, R. Juvenile Granulosa Cell Tumor of the Testis: Report of Two Cases in Newborns. J. Pediatr. Surg., 32:752-3, 1997.

Crump, W. D. Juvenile granulosa cell (sex cord-stromal) tumor of fetal testis. J. Urol., 129(5):1057-8, 1983.

Dudani, R.; Giordano, L.; Sultania, P.; Jha, K.; Florens, A. \& Joseph, T. Juvenile granulosa cell tumor of testis: case report and review of literature. Am. J. Perinatol., 25:229-31, 2008.

Fagin, R.; Berbescu, E.; Landis, S.; Strumpf, K. \& Patil, $\mathrm{U}$. Juvenile granulosa cell tumor of the testis. Urology, 62(2):351, 2003.

Lawrence, W. D.; Young, R. H. \& Scully, R. E. Juvenile granulosa cell tumor of the infantile testis: a report of 14 cases. Am. J. Surg. Pathol., 9:87-94, 1985.

Levy, D.; Kay, R. \& Elder, J. Neonatal testis tumors: a review of the prepubertal testis tumor registry. J. Urol., 151(3):715-7, 1994.

Lin, K. H.; Lin, S. E. \& Lee, L. M. Juvenile granulosa cell tumor of adult testis: a case report. Urology, 72(1):230.e11-3, 2008.

Metcalfe, P. D.; Farivar-Mohseni, H.; Farhat, W.; McLorie, G.; Khoury, A. \& Bagli, D. J. Pediatric testicular tumors: contemporary incidence and efficacy of testicular preserving surgery. J. Urol., 170:2412-6, 2003.

Peterson, Ch. \& Skoog, S. Prenatal diagnosis of juvenile granulosa cell tumor of the testis. J. Pediatr. Urol., 4:472-4, 2008.

Tanaka, Y.; Sasaki, Y. \& Tachibana, K. Testicular juvenile granulosa cell tumor in an infant with $\mathrm{X} / \mathrm{XY}$ mosaicism clinically diagnosed as true hermaphroditism. Am. J. Surg. Pathol., 18:316-22, 1994. 
TAPIA, E. O.; DELGADO, S. M. C.; BELLOLIO, J. E. \& VILLASECA, H. M. Tumor de células de la granulosa del testículo, tipo juvenil: reporte de un caso y revisión de la literatura. Int. J. Morphol., 28(2):477-482, 2010.

Thomas, J. C.; Ross, J. H. \& Kay, R. Stromal testis tumors in children: a report from the prepubertal testis tumor registry. J. Urol., 166:2338-40, 2001.

Young, R. H.; Lawrence, W. D. \& Scully, R. E. Juvenile granulosa cell tumor-Another neoplasm associated with abnormal chromosomes and ambiguous genitalia. A report of three cases. Am. J. Surg. Path., 9:737-43, 1985.

\author{
Dirección para correspondencia: \\ Dr. Oscar Tapia E. \\ Departamento de Anatomía Patológica \\ Facultad de Medicina \\ Universidad de La Frontera. \\ Manuel Montt 112 \\ Código Postal 478-1176 \\ Temuco \\ CHILE
}

Email: otescalona@gmail.com

Recibido : 27-01-2010

Aceptado: 04-05-2010 